\title{
Oral health status in children with familial Mediterranean fever
}

\author{
Pelin Esmeray ${ }^{1 \oplus}$, Tülin İleri Keçeli ${ }^{2 \oplus}$, Meryem Tekçiçek ${ }^{2 \oplus}$, Ezgi Deniz Batu ${ }^{3 \oplus}$, \\ Zehra Serap Arıc1 ${ }^{4 \oplus}$, Hande Konşuk Ünlü ${ }^{5 \oplus}$, Seza Özen ${ }^{3 \oplus}$, Yelda Bilginer ${ }^{3 \oplus}$
}

${ }^{1}$ Department of Pediatrics, Erzurum Training and Research Hospital, Erzurum; ${ }^{2}$ Department of Pediatric Dentistry, Hacettepe University Faculty of Dentistry, Ankara; ${ }^{3}$ Department of Pediatrics, Division of Pediatric Rheumatology, Hacettepe University Faculty of Medicine, Ankara; ${ }^{4}$ Şanluurfa Training and Research Hospital, Department of Pediatric Rheumatology, Şanlurfa; ${ }^{5}$ Hacettepe University Institute of Public Health, Ankara, Turkey.

\begin{abstract}
Background. Familial Mediterranean fever (FMF) is the most common hereditary autoinflammatory disease. We aimed to investigate the oral health status and oral hygiene habits in children with FMF.

Methods. In this cross-sectional study, 199 children with FMF, aged between 3-18 years, were included. Demographic findings and oral hygiene habits of children were questioned by face-to-face interview. Oral health status of patients was evaluated using decay-missing-filled index [DMFT (decay-missing-filled teeth), DMFS (decay-missing-filled teeth) for permanent; dmft, dmfs for primary teeth], the International Caries Detection and Assessment System (ICDAS-II) index, PUFA / pufa index [the presence of severely decayed teeth with visible pulpal involvement $(\mathrm{P} / \mathrm{p})$, ulceration caused by dislocated tooth fragments $(\mathrm{U} / \mathrm{u})$, fistula $(\mathrm{F} / \mathrm{f})$ and abscess (A/a)], gingival (GI) and plaque index (PI). In addition to these, occlusion, oral soft and hard tissues were examined.

Results. One-hundred-nine (54.8\%) of children had at least one decayed permanent tooth and $81.2 \%$ of children had at least one decayed primary tooth. The mean DMFT was $1.91 \pm 2.45$, DMFS was 3.1 \pm 4.49 , dmft was 3.95 \pm 3.54 , dmfs was $8.62 \pm 8.88$, PI was $1.17 \pm 0.44$, GI was $0.85 \pm 0.39$. Aphthous mouth ulcer occurred in 19 (9.5\%) patients. Recurrent aphthous mouth ulcers were more frequent among patients with one exon-ten and one exon-two mutations than patients with one exon-10 mutation, two exon-ten mutations, or two exon-2 mutations (61.1\% vs. $47.9 \%, 26.1 \%, 20 \%$, respectively $\mathrm{p}<0.001$ ). Tooth decay was more frequent among patients who had attacks in the last six months than those who did not have any attacks during the last six months (97.4\% vs. 87.7\%, $\mathrm{p}=0.017)$.
\end{abstract}

Conclusion. Dental caries and periodontal disease, which are public health problems, were seen at a high percentage of children with FMF in our study.

Key words: familial Mediterranean fever, dental caries, periodontal disease, oral hygiene.

Familial Mediterranean fever (FMF) is the most common monogenic autoinflammatory disease worldwide with an increased incidence among Arabs, Jews, Turks, and Armenians. ${ }^{1,2}$ FMF is characterized by recurrent, un-provoked, and self-limited attacks of fever (6-72 hours) resulting from mutations in the $M E F V$

\footnotetext{
Yelda Bilginer

yeldabilginer@yahoo.com
}

Received 23rd September 2019, revised 26th May 2020, accepted 12th September 2020.
(MEditerranean FeVer) gene on chromosome 16p. ${ }^{3}$ The attacks are usually accompanied by serositis. Oral manifestations such as recurrent aphthous mouth ulcers are commonly observed in autoinflammatory diseases such as PFAPA (periodic fever aphthous stomatitis pharyngitis adenitis) syndrome and mevalonate kinase deficiency; 4 ,5 however, these along with periodontitis may also occur in FMF. The dysregulation of cellular immunity is blamed to be underlying etiology of recurrent aphthous mouth ulcer and colchicine is suggested to be 
effective in aphthous mouth ulcer treatment, since it binds to microtubular proteins and impairs the movement and phagocytosis of granulocytes. However, the studies about oral findings in FMF patients are scarce, and the real frequency of aphthous mouth ulcer remains unknown. Therefore, we aimed to evaluate oral health status and oral hygiene habits of the pediatric FMF patients and the effect of oral and dental health throughout the course of the disease.

\section{Material and Methods}

The study was designed as a cross-sectional survey between May and October 2016. In this study, pediatric FMF patients were referred consecutively to the Pediatric Rheumatology and Department of Pediatric Dentistry outpatient clinics. The study was approved by the Hacettepe University Non-Interventional Clinical Researches Ethics Board (GO-16/187-48; approval date, $10^{\text {th }}$ May 2016). Informed consent was obtained from the all patients. Patients were classified as having FMF according to pediatric FMF criteria. $^{6}$ Demographic data, clinical manifestations, and $M E F V$ variant analysis were documented by medical file screening and face-to-face interviews. $M E F V$ gene variant analysis was performed with Sanger sequencing and 12 variants (E148Q, P369S, F479I, M680I (G-C), M680I (G-A), I692del, M694V, M694I, K695R, V726A, A744S, R761H) were checked in the MEFV gene in the Department of Medical Biology. The disease severity and activity were assessed by the International Severity Scoring system for FMF (ISSF) ${ }^{7}$ and autoinflammatory disease activity index (AIDAI), respectively. ${ }^{8}$ Furthermore, parents were questioned in terms of socioeconomic status, the level of education, oral hygiene, and oral hygiene habits. Oral health status of patients was evaluated from one operator, using decay-missing-filled index (DMFT, DMFS, dmft, dmfs), the International Caries Detection and Assessment System (ICDAS-II) index, PUFA/pufa indices, gingival index (GI) and plaque index (PI). Oral soft tissues were also examined. Decay-missingfilled index describes the prevalence of dental caries in an individual. ${ }^{9,10}$ While DMFT (decaymissing-filled teeth)/DMFS (decay-missingfilled surfaces) is used for permanent teeth, $\mathrm{dmft} / \mathrm{dmfs}$ is used for primary teeth. ICDAS-II is a clinical scoring system which allows detection and assessment of caries activity. ${ }^{11,12}$ The PUFA index which is used for assessing the presence of oral conditions resulting from untreated caries, records the presence of severely decayed teeth with visible pulpal involvement $(\mathrm{P} / \mathrm{p})$, ulceration caused by dislocated tooth fragments $(\mathrm{U} / \mathrm{u})$, fistula $(\mathrm{F} / \mathrm{f})$ and abscess $(\mathrm{A} / \mathrm{a}) .{ }^{13}$ Plaque index estimates the status of oral hygiene by measuring dental plaque and gingival index (GI) scores gingival inflammation. ${ }^{14,15}$

\section{Statistical analyses}

Statistical analysis was performed using IBM SPSS Statistics Version 23.0. The goodness of fit test of numeric variables to normal distribution was determined using Shapiro-Wilk test $(n \leq 50)$ and Kolmogorov-Smirnov test $(n>50)$. Equality of variances of numeric variables was tested by Levene's test. Numeric variables were given as mean \pm standard deviation (SD) if normality assumption was satisfied; median (minimummaximum) was presented, otherwise. Categorical variables were reported as count and percentages. One-way ANOVA (when homogeneity of variances assumption was satisfied) was performed to test the difference between more than two independent groups for normally-distributed data. When parametric conditions were not met, Kruskal-Wallis test was used to assess the difference between more than two independent groups. Pearson chi-square tests were conducted to examine bivariate differences between categorical variables where the assumption of the expected count less than 5 should not exceed $20 \%$ for variables was satisfied, if otherwise exact chisquare test was used. A p-value below 0.05 was accepted as significant. 


\section{Results}

One-hundred-ninety-nine children, aged between 3 and 18 years, participated in the study. The mean age of the children was $10.82 \pm 4.07$ years and $115(57.8 \%)$ of them were male. The mean age at symptom onset, and current age was $4.79 \pm 3.73$ and $6.05 \pm 3.6$ years, respectively. Among 199 patients, age at symptom onset was $\leq 5$ years in $10.6 \%(n=21)$, $6-11$ years in $46.2 \%(\mathrm{n}=92)$ and $\geq 12$ years in $43.2 \%(n=86) ; 84.4 \%(n=168)$ of patients had fever, $78.4 \% \quad(n=156)$ had abdominal pain, $57.8 \% \quad(n=115)$ had arthralgia, 20.6\% $(n=41)$ had arthritis, $12.6 \%(\mathrm{n}=25)$ had chest pain, and $7.5 \%(n=15)$ had erysipelas-like erythema. The median AIDAI score was 0 (range: 0-9). The median number of attacks during the last six months and attack duration was 0 (range: 0-19) and 2 days (range: 0-7), respectively. At the attack free period, the median leukocyte count, erythrocyte sedimentation rate, and CRP levels were $6,900 / \mathrm{mm}^{3}$ (range: $3,500-14,600$ ), $7 \mathrm{~mm} /$

Table I. Descriptive characteristics of parents.

\begin{tabular}{lc}
\hline Characteristics & $\mathrm{n}(\%)$ \\
\hline Parents' education status (mother, N=197) & \\
Illiterate & $5(2.6)$ \\
Literate & $4(3.0)$ \\
Primary school & $72(36.4)$ \\
Middle school & $44(22.7)$ \\
High school & $52(26.3)$ \\
University & $18(9.1)$ \\
Post graduate & $2(1.0)$ \\
Parents' education status (father, N=196) & \\
Illiterate & $5(2.5)$ \\
Literate & $54(27.4)$ \\
Primary school & $35(17.8)$ \\
Middle school & $66(33.5)$ \\
High school & $28(14.7)$ \\
University & $8(4.1)$ \\
Working status of mother (N=197) & \\
Yes & $41(20.7)$ \\
No & $156(79.3)$ \\
Working status of father (N=196) & \\
Yes & $180(91.9)$ \\
No & $16(8.1)$ \\
\hline
\end{tabular}

hour (range: 0-79), and $0.2 \mathrm{mg} / \mathrm{dl}$ (range: 0.119), respectively. The descriptive characteristics of the parents are summarized in Table I.

Among 199 patients, 96.5\% ( $\mathrm{n}=192)$ had their own toothbrushes. However, $49.7 \% \quad(n=99)$ of them did not brush regularly. 64 (32.2\%) patients brushed their teeth once a day, while only $35(17.6 \%)$ patients brushed their teeth two or more times a day. One-hundred-sixtyseven $(83.9 \%)$ children reported that they did not have regular dentist visits and they visited the dentist only when they had a complaint. There was no statistically significant difference between the educational status of the mother or father and going to the dentist ( $\mathrm{p}=0.055$ and $\mathrm{p}=0.36$, respectively). There was a statistically significant high rate of going to the dentist in employed mothers but a similar relationship was not established for employed fathers $(12.8 \%$ vs. $26.8 \%$; $p=0.028$, and $6.3 \%$ vs. $16.1 \%$; $p=0.474$, respectively).

Tongue pathologies were observed in 65 (32.7\%) patients. The most common tongue pathologies were as follows: coated tongue (56.9\%), fissured tongue $(27.7 \%)$, and geographic tongue $(9.2 \%)$. The mean DMFT, DMFS, dmft, dmfs indices were $1.91 \pm 2.45,3.1 \pm 4.49,3.95 \pm 3.54,8.62 \pm 8.88$, respectively. One-hundred-nine (54.8\%) children had at least one decayed permanent tooth and $81.2 \%$ of children had at least one decayed primary tooth. According to ICDAS II index, $54.3 \%(n=108)$ of the patients had a score of 5 and $29.1 \%(n=58)$ had a score of 2 (score 5 presents distinct cavity with visible dentin and score 2 presents distinct visual changes in enamel). According to the PUFA/pufa index, in $\leq 5$ years only 1 tooth had "p score" $(4.8 \%)$ and 1 tooth had "f score" (4.8\%), in $\geq 12$ years 2 teeth had "P score" (2.3\%) and only 1 tooth had "F score" (1.2\%), in 6-11 years who were in mixed dentition 9 teeth $(9.8 \%)$ had "p score", 7 teeth $(7.6 \%)$ had "f score" and 4 teeth had (4.3\%) "a score" resulting from untreated caries.

The mean of PI was $1.17 \pm 0.44$ and the mean of GI was $0.85 \pm 0.39$. During clinical examinations, aphthous mouth ulcer were observed among $9.5 \%(n=19)$ of patients. Furthermore, parents 
reported recurrent aphthous mouth ulcer in $77(38.7 \%)$ children; $91.5 \%(n=182)$ of children did not have dental trauma in the past. Flush terminal plane in primary dentition and Class 1 molar occlusion in permanent dentition are normal occlusion types in posterior teeth. Flush terminal plane was the most common occlusion relation in primary dentition $(55.3 \%$, 21/38) and Class 1 molar occlusion relation $(73.9 \%, 105 / 142)$ in permanent dentition in the right side. However, in the left side, 16 patients $(44.4 \%$; 16/36) had flush terminal occlusion relation in primary dentition and 88 patients (62.8\%; 88/140) had Class 1 molar occlusion relation in permanent dentition.

The most prevalent parafunctional oral habit was nail biting $(20.6 \% ; n=41)$ and $7.5 \%(n=15)$ of patients had chromogenic bacteria discoloration on their teeth.

When patients were compared according to $M E F V$ mutations, there was no differences in terms of tooth decay, presence of aphthous mouth ulcer during the examination, or DMFT, DMFS, dmft, dmfs parameters, PI, and GI scores between groups. However, recurrent aphthous mouth ulcers were more frequent among patients with one exon-ten and one exon-two mutations than patients with one exon-10 mutation, two exon-ten mutations, or two exon- 2 mutations ( $61.1 \%$ vs. $47.9 \%, 26.1 \%$, $20 \%$, respectively $\mathrm{p}<0.001$ ). (Table II). There was no significant difference with regards to oral health when we compared the patients according to socioeconomic and educational status of their parents. Tooth decay was more frequent among patients who had attacks in the last six months than those who did not have any attacks during the last six months $(97.4 \%$ vs. $87.7 \%$, $\mathrm{p}=0.017)$. However, aphthosis during clinical examination and recurrent aphthous mouth ulcers were not significantly associated with attack frequency in the last six months ( $37.9 \%$ vs. $47.6 \%$, $\mathrm{p}=0.385$, and $38.9 \%$ vs. $38.8 \%$, $\mathrm{p}=0.986$, respectively).

Table II. Comparison of oral and dental findings of children with familial Mediterranean fever (FMF) according to $M E F V$ mutations $\left(\mathrm{N}=187^{\sharp}\right)$

\begin{tabular}{|c|c|c|c|c|c|}
\hline \multirow[b]{2}{*}{ Findings } & \multicolumn{4}{|c|}{ Groups according to presence of mutations } & \multirow[b]{2}{*}{$P$ value } \\
\hline & $\begin{array}{l}\text { Two exon-10 } \\
\text { mutations }(n=111)\end{array}$ & $\begin{array}{c}\text { One exon-10 } \\
\text { and one exon-2 } \\
\text { mutations }(n=18)\end{array}$ & $\begin{array}{l}\text { Two exon-2 } \\
\text { mutations }(n=10)\end{array}$ & $\begin{array}{c}\text { One exon-10 } \\
\text { mutation }(n=48)\end{array}$ & \\
\hline Tooth decay, n (\%) & $76(68.5)$ & $12(66.7)$ & $8(80)$ & $30(62.5)$ & 0.445 \\
\hline $\begin{array}{l}\text { Number of attacks } \\
\text { during last six months* }\end{array}$ & $0(0-15)$ & $0(0-6)$ & $0(0-3)$ & $0(0-19)$ & 0.586 \\
\hline DMFT* $^{*}$ & $1(0-9)$ & $2(0-8)$ & $2(0-10)$ & $0(0-12)$ & 0.091 \\
\hline DMFS $^{*}$ & $1(0-23)$ & $2(0-9)$ & $2(0-10)$ & $0(0-23)$ & 0.132 \\
\hline $\mathrm{dmft}^{*}$ & $3(10-15)$ & $1.5(0-7)$ & $3(21-11)$ & $4(0-13)$ & 0.266 \\
\hline $\mathrm{dmfs}^{*}$ & $6(0-43)$ & $3.5(20-22)$ & $4(1-30)$ & $7(0-35)$ & 0.815 \\
\hline Plaque index* & $1.23(0.00-2.25)$ & $1.16(0.35-1.74)$ & $1.23(0.00-1.50)$ & $1.27(0.00-2.17)$ & 0.949 \\
\hline Gingival index** & $0.86 \pm 0.41$ & $0.82 \pm 0.33$ & $0.86 \pm 0.39$ & $0.80 \pm 0.39$ & 0.831 \\
\hline ISSF* & $1(0-6)$ & $0.5(0-3)$ & $0.5(0-2)$ & $0(0-2)$ & 0.102 \\
\hline AIDAI* $^{*}$ & $0(0-9)$ & $0(0-6)$ & $0(0-2)$ & $0(0-8)$ & 0.181 \\
\hline $\begin{array}{l}\text { Recurrent aphthous } \\
\text { mouth ulcer, n (\%) }\end{array}$ & $29(26.1)$ & $11(61.1)$ & $2(20.0)$ & $23(47.9)$ & $<0.001$ \\
\hline
\end{tabular}

\#: Mutation analysis revealed no mutation in 12 patients.

* Values are expressed as median (minimum-maximum).

** Values are expressed as mean (standard deviation)

AIDAI: autoinflammatory disease activity index, DMFT: decay-missing-filled-teeth for permanent teeth, DMFS: decaymissing-filled-surfaces for permanent teeth, dmft: decay-missing-filled-teeth for temporary teeth, dmfs: decay-missingfilled-surfaces for temporary teeth, ISSF: international severity scoring system for familial Mediterranean fever. 


\section{Discussion}

We found that recurrent aphthous mouth ulcer was more common in patients who had one exon-10 and one exon-2 mutations and patients who had attacks at the last six months had significantly higher frequency of dental caries.

There are only a few studies on oral health in adult FMF patients and these are mostly focused on periodontitis. ${ }^{16,17}$ In a study by Sogur et al. ${ }^{18}$ numbers of extracted teeth and filled teeth were found to be significantly higher in the FMF group compared to healthy controls and a study by Cengiz et al. ${ }^{19}$ showed that GI and PI indices were higher in FMF patients with amyloidosis compared to patients without amyloidosis.

According to the oral-health-related survey in our country, caries prevalence was $69.8 \%$ in 5 -year-olds, $61.1 \%$ in 12 -years-olds and $61.2 \%$ in 15-years-olds while dmft was 3.7, DMFT was 2.7, and DMFT was 2.3, respectively among these ages. ${ }^{20,21}$ In our FMF patients, frequency of tooth decay was similar to that in healthy children $(54.8 \%$ had at least one decayed permanent tooth and 81.2 had at least one decayed primary tooth). In healthy populations, $45 \%$ of 5 -yearolds, $44.6 \%$ of 12 -year-olds and $38.2 \%$ of 15 -yearolds report not brushing their teeth regularly. Moreover, in healthy populations only $4.4 \%$ of 5 -year-olds, $1.4 \%$ of 12 -year-olds and $1.8 \%$ of 15 -year-olds had visited a dentist regularly. ${ }^{21}$ Similarly, most of our patients (83.9\%) reported that they did not have regular dentist visits and did not brush regularly (49.8\%). Interestingly, neither the oral health nor the dentist visits differed according to the educational status of parents. It is possible that we could not demonstrate a significant difference since the number of patients was limited.

Previously, Kone Paut et al. ${ }^{22}$ compared patients with different $M E F V$ mutations with regards to mucocutaneous findings and did not find any significant difference in the frequency of oral aphthous lesions. Contrary to this study, we have demonstrated that patients who had one exon-10 and one exon- 2 mutations had recurrent aphthous mouth ulcers more frequently. Ours is an interesting finding since oral aphthous ulcer was thought to be a significant component of PFAPA syndrome rather than FMF. However, in Mediterranean countries, we are aware that FMF patients may present with a PFAPA-like phenotype at early ages. ${ }^{22}$

FMF is a monogenic disease, however the course of the disease varies among the patients. ${ }^{24}$ In recent years, researches have focused on the epigenetic factors affecting the phenotype of the disease. Microbiota is one of the epigenetic factors probably contributing to disease severity. A study by Khachatryan et al. ${ }^{25}$ previously demonstrated that the gut microbiota were different during attack and attack-free periods as well as between FMF patients and healthy controls. However, the effect of oral microbiota is still unknown. In the presented study, we observed higher frequency of tooth decay among patients that have had attacks in the last six months. It is tempting to speculate the effect of oral microbiota.

Our study is limited by the confounding factors associated with a small sample size and lack of aged-matched healthy controls.

In conclusion, we evaluated the oral health in children with FMF. We have observed that dental caries was more frequent in patients with a more active disease (with attacks in the last six months). It should be kept in mind that in all age groups and in all kinds of chronic diseases, oral health is affected by underlying disease, and oral health could also affect the course of the underlying disease. Therefore, it is critical for physicians to have a holistic approach while evaluating patients with chronic diseases.

\section{Acknowledgement}

None.

\section{Author contribution}

The authors confirm contribution to the paper as follows: study conception and design: Seza 
Özen, Yelda Bilginer and Meryem Tekçiçek; data collection Pelin Esmeray, Ezgi D. Batu, Zehra S. Arıcı and Tülin İ. Keçeli, analysis and interpretation of results: Hande K. Ünlü, Pelin Esmeray, Ezgi D. Batu, Yelda Bilginer. All authors reviewed the results and approved the final version of the manuscript.

\section{Source of funding}

No funding support was received for this study.

\section{Conflict of interest}

The authors declare no conflict of interest.

\section{REFERENCES}

1. Zadeh N, Getzug T, Grody WW. Diagnosis and management of familial Mediterranean fever: integrating medical genetics in a dedicated interdisciplinary clinic. Genet Med 2011; 13: 263-269.

2. Ozen S, Batu ED, Demir S. Familial Mediterranean fever: Recent developments in pathogenesis and new recommendations for management. Front Immunol 2017; 8: 253

3. Sönmez HE, Batu ED, Özen S. Familial Mediterranean fever: current perspectives. Inflamm Res 2016; 9: 1320.

4. Batu ED, Kara Eroglu F, Tsoukas P, et al. Periodic fever, aphthosis, pharyngitis, and adenitis syndrome: analysis of patients from two geographic areas. Arthritis Care Res (Hoboken) 2016; 68: 18591865.

5. Zhang S. Natural history of mevalonate kinase deficiency: a literature review. Pediatr Rheumatol Online J 2016; 14: 30.

6. Yalcinkaya F, Ozen S, Ozcakar ZB, et al. A new set of criteria for the diagnosis of familial Mediterranean fever in childhood. Rheumatology (Oxford) 2009; 48: 395-398.

7. Demirkaya E, Acikel C, Hashkes P, et al; FMF Arthritis Vasculitis and Orphan Disease Research in Pediatric Rheumatology (FAVOR). Development and initial validation of international severity scoring system for familial Mediterranean fever (ISSF). Ann Rheum Dis 2016; 75: 1051-1056.
8. Piram M, Kone-Paut I, Lachmann HJ, et al. Validation of the auto-inflammatory diseases activity index (AIDAI) for hereditary recurrent fever syndromes. Ann Rheum Dis 2014; 73: 2168-2173.

9. World Health Organisation. Oral Health Surveys - Basic Methods. 4th ed. Geneva: World Health Organisation. Availeble at: https://apps.who.int/iris/ handle/10665/41905 (Accessed on October 10, 2018)

10. Baelum V, Luan WM, Chen X, Fejerskov O Predictors of tooth loss over 10 years in adult and elderly Chinese. Community Dent Oral Epidemiol 1997; 25: 204-210.

11. Diniz MB, Rodrigues JA, Hug I, Cordeiro Rde C, Lussi A. Reproducibility and accuracy of the ICDASII for occlusal caries detection. Community Dent Oral Epidemiol 2009; 37: 399-404.

12. Ismail AI, Sohn W, Tellez M, et al. The International Caries Detection and Assessment System (ICDAS): an integrated system for measuring dental caries. Community Dent Oral Epidemiol 2007; 35: 170-178.

13. Monse B, Heinrich-Weltzien R, Benzian H, Holmgren $C$, van Palenstein Helderman W. PUFA--an index of clinical consequences of untreated dental caries. Community Dent Oral Epidemiol 2010; 38: 77-82.

14. Silness J, Loe H. Periodontal disease in pregnancy. II. Correlation between oral hygiene and periodontal condtion. Acta Odontol Scand 1964; 22: 121-135.

15. Loe H, Silness J. Periodontal disease in pregnancy. I. Prevalence and severity. Acta Odontol Scand 1963; 21: 533-551.

16. Sezer U, Senyurt SZ, Ozdemir EC, et al. Relationship between periodontal destruction and gene mutations in patients with familial Mediterranean fever. Clin Rheumatol 2016; 35: 1841-1847.

17. Bostanci V, Toker H, Senel S, Sahin S. Prevalence of periodontal disease in patients with Familial Mediterranean Fever: a cohort study from central Turkey. Quintessence Int 2014; 45: 743-748.

18. Sogur E, Onem E, Kalfa M, et al. Oral health and oral quality of life in inactive patients with familial Mediterranean fever without amyloidosis. Clin Exp Rheumatol 2013; 31 (3 Suppl 77): 15-19.

19. Cengiz MI, Bagci H, Cengiz S, Yigit S, Cengiz K. Periodontal disease in patients with familial Mediterranean fever: from inflammation to amyloidosis. J Periodontal Res 2009; 44: 354-361.

20. Gokalp SG, Dogan BG, Uzamış Tekcicek M, Berberoglu A, Unluer S. National survey of oral health status of children and adults in Turkey. Community Dent Health 2010; 27: 12-17. 
21. Gökalp S, Güçiz Doğan B, Tekçiçek M, Berberoğlu A, Unlüer $S$. Beş, on iki ve on beş yaş çocukların ağız diş sağlığ1 profili, Türkiye-2004. Hacettepe Üniversitesi Dişhekimliği Fakültesi Dergisi 2007; 31: 3-10.

22. Kone Paut I, Dubuc M, Sportouch J, Minodier P, Garnier JM, Touitou I. Phenotype-genotype correlation in 91 patients with familial Mediterranean fever reveals a high frequency of cutaneomucous features. Rheumatology (Oxford) 2000; 39: 12751279.

23. Butbul Aviel Y, Harel L, Abu Rumi M, et al. Familial Mediterranean fever is commonly diagnosed in children in Israel with periodic fever aphthous stomatitis, pharyngitis, and adenitis syndrome. J Pediatr 2019; 204: 270-274.
24. Ozen S, Batu ED. The myths we believed in familia Mediterranean fever: what have we learned in the past years? Semin Immunopathol 2015 ;37: 363-369.

25. Khachatryan ZA, Ktsoyan ZA, Manukyan GP, Kelly D, Ghazaryan KA, Aminov RI. . Predominant role of host genetics in controlling the composition of gut microbiota. PloS One 2008; 3: e3064. 